\title{
LA REGULACIÓN Y LA PRÁCTICA DEL REFERÉNDUM EN SUIZA: UN ANÁLISIS DESDE LAS CRÍTICAS A LA INSTITUCIÓN DEL REFERÉNDUM
}

\author{
The Regulation and Practice of the Referendum in \\ Switzerland: An Analysis of Criticisms of the Institution
}

\author{
EVA SÁENZ ROYO \\ Universidad de Zaragoza \\ Revista de Estudios Políticos \\ ISSN-L 0048-7694, núm. 171, Madrid, enero/marzo (2016), pp. 71-104 \\ http://dx.doi.org/10.18042/cepc/rep. 171.03 \\ Cómo citar/Citation \\ Sáenz Royo, E. (2016). La regulación y la práctica del referéndum en Suiza: \\ un análisis desde las críticas a la institución del referéndum. \\ Revista de Estudios Políticos, 171, 71-104. \\ doi: http://dx.doi.org/10.18042/cepc/rep.171.03
}

\section{Resumen}

Ha sido habitual en la doctrina subrayar las disfuncionalidades que la práctica del referéndum conlleva en los sistemas democráticos. Stephen Tierney ha sintetizado en tres estas disfuncionalidades denunciadas. En primer lugar, el control del proceso ejercido por unas élites y con ello la posible manipulación de su resultado (the elite control syndrome). En segundo lugar, que hay una tendencia en los procesos de referéndum a agregar prejuicios, en lugar de formar opiniones a través de la deliberación (the deliberation deficit). Y, en tercer lugar, se señala que los referéndums consolidan mayorías, sin tener en cuenta las minorías ni los intereses individuales (the majoritarian danger). El objeto de este artículo es analizar la regulación y la práctica del referéndum en el país con mayor experiencia en este campo y, con ello, tratar de discernir hasta qué punto las críticas a la institución del referéndum se corresponden o no con la realidad en Suiza.

\section{Palabras clave}

Referéndum; iniciativa popular; Suiza; democracia directa. 


\begin{abstract}
It has been common in the literature to emphasize the dysfunctions that the practice of the referendum can lead to in democratic systems. Stephen Tierney has synthesized three alleged dysfunctions. First, the referendum can imply the control of the process being exercised by a few elites and the possible manipulation of the result (the elite control syndrome). Second, the referendum can tend to aggregate prejudices, rather than forming opinions through processes of deliberation (the deliberation deficit). Third, the referendum consolidates majorities, without taking into account either minority or individual interests (the majoritarian danger). The aim of this article is to analyze the regulation and the practice of the referendum in Switzerland, the country with most experience of this field, to try to discern up to what point the critiques of the institution of the referendum correspond to the reality of the Swiss experience.
\end{abstract}

\title{
Key words
}

Referendum; popular initiative; Switzerland; direct democracy. 


\section{SUMARIO}

I. INTRODUCCIÓN. II. REGULACIÓN CONSTITUCIONAL Y LEGAL DEL REFERÉNDUM Y LA INICIATIVA POPULAR DE ÁMBITO FEDERAL EN SUIZA. 1. La regulación constitucional del referéndum y de la iniciativa popular de ámbito federal. 2. La regulación legal del referéndum y de la iniciativa popular de ámbito federal. III. LA PRÁCTICA DEL REFERÉNDUM EN SUIZA. 1. La escasa participación en referéndums. 2. ¿̇Es el referéndum un instrumento de confrontación de legitimidades y de debilitamiento de los partidos políticos? 3. ¿̇Es el referéndum un instrumento para la manipulación de las élites? 4. El déficit deliberativo en el referéndum o el mito del ciudadano incompetente. 5. ¿̇Es el referéndum un instrumento de consolidación de mayorías? 6. Un breve apunte sobre los efectos económicos del referéndum en Suiza. IV. ALGUNAS CONCLUSIONES. FueNtes dOCUMENTALES. Biblografía.

«Los obstáculos de la democracia tienen poco que ver con la cultura o la religión, y sí mucho más con el deseo de aquellos en el poder de mantener sus posiciones a cualquier coste».

Kofi Annan, ex secretario general de las Naciones Unidas.

\section{INTRODUCCIÓN}

Una de las principales características del régimen suizo es la regularidad con la que los ciudadanos son llamados a expresar su opinión sobre leyes o modificaciones constitucionales a través de referéndum. Es el país con el mayor número de referéndums realizados en el ámbito nacional ${ }^{1}$. Ello hace del modelo democrático suizo un modelo con rasgos específicos respecto a los modelos clásicos de democracia representativa. Y esto hace de Suiza un caso especialmente interesante para analizar la teoría y la práctica del referéndum y tratar de discernir los principales problemas que acarrea el uso de este instrumento, así como las soluciones arbitradas.

Al margen de la tradición suiza de la Landsgemeinde ${ }^{2}$, los instrumentos de democracia directa aparecen en Suiza no como una alternativa a la demo-

1 De los 2.703 referéndums celebrados en todo el mundo en el ámbito nacional a octubre de 2015, 612 se han celebrado solo en Suiza.

2 Institución que como residuo histórico pervive en los cantones de Glaris y de Appenzell Rodas interiores y que consiste en que el poder legislativo no se ejerce a 
cracia representativa, sino como complemento a la misma. Hay que subrayar que es el primer país europeo que garantiza constitucionalmente el sufragio universal masculino — excluido a los judíos hasta 1866- (Dardanelli, 2011: 150) y actualmente la mayoría de la legislación es aprobada por el parlamento sin interferencia de los votantes. Aproximadamente el 93 por ciento de las leyes formalmente sujetas a la opción del referéndum son aprobadas sin el mismo (Kriesi y Trechsel, 2008: 57; Serdült, 2010: 165). Se trata, pues, de un modelo de democracia representativa en la que se introducen instrumentos de democracia directa.

Los instrumentos de democracia directa en Suiza son básicamente dos: la iniciativa popular y el referéndum. Mientras que la iniciativa popular tiene como objetivo introducir en la agenda de las instituciones nuevas cuestiones - concretamente, reformas constitucionales-, el referéndum se utiliza para que los ciudadanos suizos opinen o bien sobre las iniciativas populares o sobre decisiones tomadas desde el Parlamento. A pesar de la distinción, se trata de dos instrumentos que están muy ligados, ya que la iniciativa popular en Suiza está concebida para iniciar un proceso de reforma constitucional y como tal —en la mayoría de los casos- será sometida a referéndum. De esta manera, en la práctica, se convierte en una propuesta de una fracción del cuerpo electoral para someter una cuestión —en concreto, una reforma constitucionala referéndum. $Y$ es precisamente en esta virtualidad de impulso ciudadano de referéndum donde analizaremos también la iniciativa popular en Suiza.

\section{REGULACIÓN CONSTITUCIONAL Y LEGAL DEL REFERÉNDUM Y LA INICIATIVA POPULAR DE ÁMBITO FEDERAL EN SUIZA ${ }^{3}$}

La historia constitucional suiza se caracteriza por una progresiva profundización y ampliación de los instrumentos de democracia directa y, en concreto, de las posibilidades de referéndum (Dardanelli, 2011: 151-153). El referéndum tal y como lo concebimos hoy fue una importación de la Revolución francesa. De esta influencia es el primer referéndum de ámbito federal que tuvo lugar en 1802 para la aprobación de la segunda constitución de la República Helvética. La previsión de referéndums para aprobar y reformar constituciones en los cantones convirtió en algo natural que se previera desde

través de representantes, sino que es el pueblo en su conjunto el que se reúne en asamblea y vota a mano alzada.

3 No será objeto de análisis la regulación y la práctica del referéndum en los diferentes cantones. 
la creación del Estado federal suizo en 1848 el referéndum obligatorio para las modificaciones de la Constitución federal. También desde sus orígenes se reconoció la iniciativa popular para la reforma completa de esta Constitución. Ambas instituciones se verían, con el paso del tiempo, ampliadas.

Tras la revisión total de la Constitución en 1874 se incorporó el referéndum facultativo en materia legislativa. Y en 1891 se introdujo la iniciativa popular para la reforma parcial de la Constitución. Ambos instrumentos fueron el producto de los movimientos democráticos que deseaban ir más allá del «parlamentarismo liberal», que se consideraba dominado por unas élites. Estos movimientos democráticos triunfaron primero en el ámbito cantonal, especialmente en Zúrich y Berna, y presionaron para su adopción en el ámbito federal, contando con el apoyo de las minorías franco-parlantes y conservadoras católicas. Consecuencia del creciente impacto en el sistema político suizo de la integración y cooperación internacional, en 1921 se introdujo el referéndum facultativo en relación con los Tratados internacionales de una duración indeterminada, cuya aplicación fue ampliada a otros tratados internacionales en 1977. Por último, como reacción al uso excesivo de la legislación de urgencia durante los años treinta y cuarenta, en 1949 se introdujo un referéndum obligatorio y facultativo relativo a las decisiones federales de ámbito general urgentes.

Esta regulación constitucional no ha sido modificada, aunque con la nueva Constitución de 1999, la actual regulación es mucho más clara. Una pequeña reforma en el año 2003 amplió el referéndum facultativo en tratados internacionales. También en el año 2003 se introdujo la llamada «iniciativa general» para casos en que la iniciativa popular no afectara a la Constitución, sino que correspondiera implementarla a través de una ley o un reglamento. No obstante, este instrumento no fue utilizado en la práctica y se abolió por referéndum celebrado el 27 de septiembre de 2009. A continuación analizaremos la regulación constitucional y legal tanto del referéndum como de la iniciativa popular de ámbito federal en Suiza.

\section{LA REGULACIÓN CONSTITUCIONAL DEL REFERÉNDUM Y DE LA INICIATIVA POPULAR DE ÁMBITO FEDERAL}

La Constitución suiza de 1999 reconoce la posibilidad de que los ciudadanos impulsen una reforma constitucional que —en la mayoría de los supuestos - será sometida a referéndum. Por una parte, los ciudadanos pueden impulsar una reforma total de la Constitución suiza, que será sometida a referéndum del pueblo (art. 138). Por otra parte, los ciudadanos pueden proponer una reforma parcial de la Constitución, que será sometida a referéndum del pueblo en caso de que la Asamblea Federal la rechace o en todo caso si constituye un proyecto articulado. En este último caso el referéndum 
se dirigirá al pueblo y a los cantones. En caso de que se presente una iniciativa en términos generales y se acepte por la Asamblea Federal, la reforma constitucional sometida a referéndum del pueblo y los cantones será la propuesta por la Asamblea (art. 139). En definitiva, se trata de reconocer una capacidad de impulso a una fracción del cuerpo electoral para someter a referéndum una reforma constitucional planteada desde la sociedad civil. Una capacidad de impulso que tiene sus dificultades y limitaciones.

Para presentar una iniciativa popular inicialmente solo se exigían 50.000 firmas y no había plazo para su recogida. En 1977 se introdujo el plazo de 18 meses junto con el incremento a 100.000 firmas. El alto número de firmas exigidas no es fácil de conseguir en los 18 meses del plazo interpuesto. De hecho, tres de cada cuatro iniciativas que se emprenden no las logran. Además, la movilización de estas firmas exigirá recursos económicos. Por otra parte, también las élites políticas tienen mecanismos para dificultarla, invalidándola por motivos formales (aunque veremos que es poco frente), dilatando la decisión sobre la misma o presentando un contraproyecto, lo que provocará la división del voto de los que quieren una reforma constitucional y facilitando la victoria a quienes deseen que las cosas continúen como estaban. Las contrapropuestas parlamentarias suelen ser menos radicales que las iniciativas populares, pero tienden a incorporar algunas de las demandas de los promotores y tener mayores probabilidades de ser aprobadas.

La Constitución define tres criterios para la admisibilidad de la iniciativa popular. Primero, la unidad de forma. Este criterio requiere que la iniciativa sea formulada como un concreto proyecto legislativo o como una proposición general. Si la propuesta contiene una mezcla de ambas, la iniciativa violará este principio. Segundo, la iniciativa debe tener unidad de materia. Este criterio requiere que cada iniciativa se dirija solo a esas cuestiones que están claramente interrelacionadas (art. 75 Ley federal de derechos políticos). En caso contrario, confundiría a los votantes del referéndum e impediría una clara expresión de su voluntad. Por tanto, se trata de una limitación estrechamente ligada al referéndum y que pretende garantizar que los ciudadanos expresen su opinión sin ambigüedades. Tercero, la iniciativa debe ser acorde con «las reglas imperativas del derecho internacional», el así denominado ius cogens. Si la iniciativa entra en conflicto con el ius cogens internacional, la Asamblea Federal puede declarar una iniciativa popular inválida y rechazar el referéndum sobre dicha iniciativa. No obstante, esta restricción material solo se refiere a "las reglas imperativas del derecho internacional», y no al derecho internacional en general. Esto significa que si una iniciativa es contraria a un tratado internacional o normas internacionales que no sean ius cogens, el parlamento no tiene autoridad para declarar esta propuesta inválida y está obligado a presentar la iniciativa a referéndum. En el caso de que el referéndum fuera aprobado y el 
contenido del mismo claramente contrario a obligaciones internacionales, se trataría de un implícito mandato al gobierno federal para denunciar el tratado internacional correspondiente.

Hay que subrayar que la Constitución suiza no introduce otras limitaciones materiales a la iniciativa popular de reforma constitucional y, por tanto, al referéndum a que dé lugar esta. Además, las limitaciones establecidas constitucionalmente para la iniciativa popular resultan en la práctica muy poco efectivas. Hasta 2014 solo ha ocurrido en cuatro ocasiones. En 1955 se declaró inválida una iniciativa sobre "Reducción temporal del gasto militar» por inejecutabilidad temporal. Por violación de unidad de temas se declararon inválidas las iniciativas "Contra el alza de precios y la inflación» en 1977 y «Por menos gasto militar y más inversión en la política de paz» en 1995. Por violación de reglas obligatorias del derecho internacional se declaró inválida en 1996 la iniciativa "Por una política sensata de asilo» (Serdült, 2014: 73; Kaufmann et al., 2007: 178).

Respecto al referéndum, la regulación constitucional en el ámbito federal se recoge en los artículos 140, 141 y 142 . Se distingue entre el referéndum obligatorio y el referéndum facultativo.

La regulación del referéndum obligatorio (art. 140) recoge las materias que obligatoriamente deberán ser sometidas a consulta o bien del pueblo, o bien del pueblo y de los cantones. Señala el artículo 140 (traducción propia):

1. Se someterán a votación del pueblo y de los cantones:

a. Las revisiones de la Constitución.

b. La adhesión a organizaciones de seguridad colectiva o a las comunidades supranacionales.

c. Las leyes federales declaradas urgentes, que estén desprovistas de base constitucional y que la duración de su validez sea superior al año; estas leyes deberán someterse a votación en el plazo de un año a contar desde su adopción por la Asamblea Federal.

2. Se someterán a la votación del pueblo:

a. Las iniciativas populares que tengan como objeto la revisión total de la Constitución.

b. Las iniciativas populares concebidas en términos generales que tengan como objeto la revisión parcial de la Constitución y que hayan sido rechazadas por la Asamblea Federal.

c. El principio de una revisión total de la Constitución, en caso de desacuerdo entre ambos Consejos.

Tal y como se comprueba, toda reforma constitucional exige que sea aprobada por referéndum tanto por el pueblo como por los cantones. En este 
caso, la mayoría cantonal está calculada sobre los votos del conjunto de la población del cantón correspondiente. Hay que señalar que, según establece el artículo 142.4, los cantones de Alto Unterwald, Bajo Unterwald, Basilea-Ciudad, Basilea-Campiña, Appenzell Rodas Exteriores y de Appenzell Rodas Interiores cuentan cada uno por medio voto. Por tanto, aunque en total sean 26 cantones, la mayoría requerida se calculará sobre 23 y se conseguirá a partir de los 12 votos.

Por otra parte, tal y como se deduce del texto constitucional, una iniciativa de revisión total de la Constitución realizada por uno de los dos Consejos que componen la Asamblea Federal (Consejo Nacional y Consejo de Estados) solo se someterá a referéndum si hay discrepancia entre ellos. En ese caso, para el inicio de tal reforma bastaría la simple mayoría de los votantes.

El referéndum facultativo se trata de un referéndum cuya iniciativa la tienen los ciudadanos (50.000) o los cantones (ocho) y se trata básicamente de un referéndum legislativo, incluyendo también tratados internacionales. Señala el artículo 141 (traducción propia):

1. Si dentro del plazo de 100 días desde la publicación oficial, 50.000 ciudadanos y ciudadanas con derecho a voto $\mathrm{u}$ ocho cantones lo requieran, lo siguiente se someterán a votación del pueblo:

a. Las leyes federales.

b. Las leyes federales declaradas urgentes cuando la duración de su validez sobrepase el año.

c. Los decretos federales, en los casos en que la constitución o la ley lo prevean.

d. Los tratados internacionales que:

1. Tengan una duración indeterminada y no sean denunciables.

2. Prevean la adhesión a una organización internacional.

3. Contengan previsiones legislativas importantes o cuya implementación requiera la promulgación de legislación federal.

El número de firmas requeridas inicialmente fueron 30.000 y debían presentarse dentro de los 90 días después de la publicación de la ley o decisión en un diario oficial. En 1977 se incrementó la exigencia a 50.000 firmas a raíz del reconocimiento del derecho de sufragio femenino en 1971 y en 1997 se extendió el plazo de presentación a los 100 días (Serdült, 2014: 72).

\section{LA REGULACIÓN LEGAL DEL REFERÉNDUM Y DE LA INICIATIVA POPULAR DE ÁMBITO FEDERAL}

La regulación constitucional es desarrollada por la Ley Federal sobre Derechos Políticos de 17 de diciembre de 1976. A diferencia de otros países don- 
de se instituyen comisiones independientes para vigilar los procedimientos de referéndum, en Suiza es el propio gobierno, la Cancillería Federal, quien aconseja a los comités de iniciativa y referéndum, revisa las listas de firmas presentadas e iniciativas populares, organiza los referéndums federales y las elecciones al Consejo Nacional, y atiende las quejas sobre las elecciones y los referéndums. También es el encargado de informar a los votantes.

Así, por ejemplo, la solicitud de referéndum debe someterse a la Cancillería Federal antes de finalizar el plazo de 100 días a contar desde la publicación oficial de la ley o decisión correspondiente. Dentro de ese plazo procederá a la recogida de firmas y su autenticación. Además, se establece que una vez se solicita el referéndum, la solicitud no puede ser retirada por los promotores. Cuando expira el plazo para la recogida de firmas, la Cancillería Federal comprueba si se ha conseguido el número de firmas válidas que establece la Constitución. Si se han conseguido menos de la mitad de las firmas requeridas, simplemente se publica que el plazo ha expirado. Si se consiguen la mitad o más de la mitad de las firmas, la Cancillería procederá a comprobar si la solicitud ha tenido o no éxito. También se establece que en el caso de que la solicitud de referéndum proceda de los cantones, es el parlamento cantonal el que tiene que decidir si hace o no la solicitud, salvo que la normativa del cantón prevea otra cosa (arts. 58 y ss.).

En el caso de la iniciativa popular para la reforma constitucional, primero deberá someterse para su examen a la Cancillería Federal, quien la publicará en el boletín oficial federal. Desde entonces se cuenta con un plazo de dieciocho meses para la recogida de las firmas. La iniciativa popular puede ser retirada por sus promotores, para lo cual se necesitará la firma de la mayoría absoluta de los mismos. Se prevé la posibilidad de condicionar la retirada de la iniciativa al éxito de una contrapropuesta legislativa del Parlamento. La Cancillería Federal debe someter a referéndum la iniciativa en el plazo de diez meses desde la votación sobre la misma en la Asamblea Federal (arts. 68 ss).

Sorprendentemente no hay en Suiza una regulación exhaustiva sobre la campaña del referéndum. No obstante, la imparcialidad en la misma está asegurada a través de la interpretación que el Tribunal Supremo ha derivado de derechos fundamentales garantizados por la Constitución como la libertad de opinión e información (art. 16), la libertad de los medios de comunicación (art. 17), la libertad de reunión (art. 22) y la libertad de asociación (art. 23). Más concretamente el artículo 34.2 de la Constitución Federal establece que la garantía de derechos políticos protege la libre formación de opinión de los ciudadanos y la expresión legítima de su voluntad. Según el Tribunal Supremo (Decision of the Federal Supreme Court 121 I 252, 255 f), este derecho no impone estrictamente neutralidad de las autoridades políticas durante el debate del referéndum. A este respecto, el Tribunal Supremo durante las úl- 
timas cinco décadas ha ido progresivamente reconociendo a las autoridades un mayor deber de involucrarse activamente en la campaña de referéndum (Serdült, 2010: 174). De hecho, el gobierno puede presentar su punto de vista y dar recomendaciones de voto. Además puede explicar su punto de vista en folletos de información oficial distribuidos a los ciudadanos junto con el material electoral. Tiene también derecho a defender su posición en un breve discurso televisado inmediatamente después de las noticias de la noche. Pero no podrá ir más allá ni gastar fondos públicos a favor de una de las opciones, salvo que el uso de esos fondos tenga base legal, haya sido autorizado por el parlamento o tenga una posición separada en los presupuestos y representantes de la autoridad pública sean miembros del comité impulsor, ya que de otro modo no hay control sobre lo que ocurre con el dinero (Decision of the Federal Supreme Court 114 Ia 427, 444; Decision of the Federal Supreme Court 114 Ia 427, 443; Serdült, 2010: 175). Por otra parte, también está obligado a resumir los argumentos tanto a favor como en contra de una propuesta y desde 1994 —aunque en práctica desde 1983 - a incluir los argumentos del comité de referéndum o de iniciativa, aunque los argumentos gubernamentales suelen recibir un espacio mayor (Serdült, 2010: 171). En la mayoría de los cantones el folleto se envía por correo a todos los votantes registrados, junto con las papeletas y el certificado que le autoriza a votar tres o cuatro semanas antes de la votación. El gobierno puede intervenir en los argumentos del comité de iniciativa o referéndum solamente si el texto es difamatorio o demasiado largo (art. 11.2 Ley Federal sobre Derechos Políticos).

Tampoco se incluyen reglas sobre la financiación, duración o medios accesibles. En Suiza los partidos políticos no reciben financiación pública, son en su mayoría asociaciones sin ánimo de lucro sometidas al derecho privado y se financian a sí mismos a través de las cuotas de sus afiliados, contribuciones de los titulares o donaciones. En el caso de las campañas de referéndum no hay obligación de revelar la identidad de los donantes ni la cantidad de dinero gastada ni por parte de los partidos políticos ni por parte de los grupos de la sociedad civil. No hay ninguna regla de transparencia en el ámbito federal.

A diferencia de otros Estados, la ley suiza tampoco determina un periodo de tiempo oficial para la campaña de referéndum. Ni se prevén reglas específicas para el acceso a los medios por los partidos políticos y organizaciones sociales durante las campañas de referéndum. No obstante, la Ley Federal sobre Radio y Televisión, aprobada el 24 de marzo de 2006, tiene previsiones que son importantes al respecto. Obliga, por ejemplo, a que todas las cadenas de radio y televisión respeten los derechos fundamentales, contribuyan a la libre formación de opinión, ofrezcan información objetiva y variada. Además las opiniones personales han de ser reconocidas como tales (art. 4). Los anuncios políticos en radio y televisión están prohibidos (art. 10). De manera 
que quedan prohibidos los anuncios de partidos políticos, candidatos o sobre cuestiones sometidas a referéndum. Los comités y los partidos políticos solo pueden gastar su dinero en posteres, correo postal y anuncios en periódicos. Además los programas de noticias y programas de actualidad política, así como los programas que están relacionados con el ejercicio de los derechos políticos en la Confederación, los cantones y las comunas no podrán ser patrocinados (art. 12.5). Para asegurar el cumplimiento de estos mandatos se nombra a un mediador independiente en cada una de las regiones lingüísticas y sus decisiones serán revisadas por una autoridad independiente establecida en el ámbito estatal (arts. 91, 82-85, 94). Según se reconoce por la generalidad de los actores políticos, esta regulación garantiza un debate justo en las campañas de referéndum (Serdült, 2010: 171).

Por último, hay que subrayar que los ciudadanos suizos que viven o se encuentran en el extranjero pueden también votar en referéndums y elecciones, y respaldar con firmas las iniciativas y referéndums (art. 3.1 de la Ley Federal, de 19 de diciembre de 1975, sobre los derechos políticos de los ciudadanos suizos que viven o se encuentran en el extranjero $\left.{ }^{4}\right)$.

\section{LA PRÁCTICA DEL REFERÉNDUM EN SUIZA}

Ha sido habitual en la doctrina subrayar las disfuncionalidades que la práctica del referéndum conlleva en los sistemas democráticos. Stephen Tierney (2012: 23) ha sintetizado en tres estas disfuncionalidades denunciadas. En primer lugar, el control del proceso ejercido por unas élites y con ello la posible manipulación de su resultado (the elite control syndrome). En segundo lugar, que hay una tendencia en los procesos de referéndum a agregar prejuicios, en lugar de formar opiniones a través de la deliberación (the deliberation deficit). Y que los referéndums consolidan mayorías, sin tener en cuenta las minorías ni los intereses individuales (the majoritarian danger). También se han señalado como críticas a la práctica del referéndum su falta de legitimidad en caso de escasa participación, que supone una confrontación de voluntades y legitimidades - la parlamentaria y la popular - y un debilitamiento de la democracia representativa o que el uso del referéndum tiene efectos económicos negativos.

4 En este mismo sentido la Ley Federal sobre Personas e Instituciones Suizas en el extranjero, de 26 de septiembre de 2014, que todavía no está en vigor cuando se escriben estas líneas. 
En las líneas que siguen analizaré la experiencia práctica del referéndum en Suiza a partir de estas críticas vertidas en general a la institución del referéndum.

\section{LA ESCASA PARTICIPACIÓN EN REFERÉNDUMS}

Con carácter general la participación en referéndums en Suiza está por debajo del 50 por ciento. Después de la Segunda Guerra Mundial se percibe un progresivo descenso de la participación desde el 60 hasta el 40 por ciento de media en los años setenta. La media en los últimos años se sitúa alrededor del 45 por ciento con una tendencia ligeramente al alza (Serdült, 2014: 81). Solo determinados referéndums han tenido una alta participación, como los relativos a la mano de obra extranjera (75 por ciento de participación en 1970 y 70 por ciento en 1974), a la supresión del ejército (69 por ciento de participación en 1989) o la adhesión al Espacio Económico Europeo (78 por ciento de participación en 1992).

Tal y como señala la doctrina, el bajo nivel de participación parece ser el precio a pagar en un sistema con fuertes instrumentos de democracia directa. Si bien la importancia del tema que se trata sí es un incentivo para una mayor participación, el nivel de abstencionismo registrado no tiene causas claras. Quizás la demasiada frecuencia de los referéndums puede ser una de ellas (Lutz, 2007: 630-631). De ahí propuestas en las que para reducir esta frecuencia señalen la necesidad de aumentar considerablemente el número de firmas exigible 5 . No obstante, el incremento del número de consultas en los últimos años no ha hecho reducir la media de participación, lo que no permite afirmar con certeza que la frecuencia sea una causa del abstencionismo. Tampoco parece relacionarse con un bajo nivel de formación de la ciudadanía, ya que mientras el nivel de formación ha ido incrementándose desde la Segunda Guerra Mundial esto no se ha traducido en un impacto positivo sobre la participación. Estudios comparados apuntan a dos circunstancias propias de Suiza para explicar esta baja participación. Por una parte, la desaparición del voto obligatorio en la mayoría de los cantones después de la Segunda Guerra Mundial o en los años setenta. Por otra parte, se apunta que la tardía adopción en Suiza del voto femenino, en 1971, puede influir en la más baja participación de este colectivo en los referéndums (Serdült, 2014: 81).

5 Se señala que el umbral de firmas necesarias para las iniciativas populares no se ha tocado desde 1977, pero sí ha aumentado considerablemente el número de electores (de 3,8 millones en 1977 a 5,1 millones en 2013). En este sentido, Serdült (2014: 80). 
También existen estudios empíricos que señalan que los canales de votación pueden incidir en la participación electoral. Durante más de un siglo el voto presencial en urna ha sido la forma más habitual en Suiza de votar en un referéndum. Sin embargo, actualmente el voto postal (introducido en el ámbito federal en 1994 y progresivamente simplificado) es la forma más habitual. De hecho, en las ciudades más del 90 por ciento de los votantes envían su voto por correo, comenzando tres o cuatro semanas antes del día de la votación (Serdült, 2014: 75). Algunos estudios han llegado a cuantificar el incremento en la participación que ha tenido el uso del correo postal en un 4,1 por ciento de media (Lüchinger et al., 2007: 186). No obstante, el incremento del voto postal también puede tener un efecto adverso respecto a la recogida de firmas. Hans-Urs Wili, experto en derechos civiles en la Cancillería Federal, está convencido de que "la tendencia hacia un mayor uso del voto postal ha tenido un efecto adverso en la recogida de firmas fuera de los centros de votación» (Kaufmann et al., 2007: 101). Curiosamente la sustitución del voto postal por el de internet no ha supuesto un incremento en la participación. Y este era precisamente el objetivo que se pretendía en Ginebra, Neuchâtel y Zúrich cuando introdujeron el voto por internet. Hasta el momento se ha observado una sustitución del voto postal por el de internet, pero no se ha detectado un incremento en la participación. No obstante, el voto por internet sí que está funcionando muy bien entre los suizos en el extranjero y es posible en todos los cantones suizos desde 2015 (Serdült, 2014: 75-76).

Tener una participación media por debajo del 50 por ciento es indudablemente una participación baja. Pero ¿̇la escasa participación ha supuesto poner en duda la legitimidad del referéndum en Suiza? Tal y como argumenta Kriesi, la baja participación no hace perder legitimidad democrática a la decisión siempre que esta baja participación no responda a una general desafección con el sistema democrático (Kriesi, 2005: 238). Pero, a tenor del grado de satisfacción mostrado por los ciudadanos suizos con su sistema, no parece que la baja participación se deba a una desafección con el sistema. Los ciudadanos suizos tienen un gran aprecio por su democracia. En un sondeo de 2001 el 90 por ciento de la población estaba muy o bastante orgulloso de su democracia y el 94 por ciento consideraba muy o bastante importante su democracia para el futuro del país (Kriesi y Trechsel, 2008: 66).

\section{2. ¿̇ES EL REFERÉNDUM UN INSTRUMENTO DE CONFRONTACIÓN DE LEGITIMIDADES Y DE DEBILITAMIENTO DE LOS PARTIDOS POLÍTICOS?}

Desde 1848 hasta 2015 ha habido 598 consultas en el ámbito federal suizo. En 219 casos se trataba de una revisión constitucional propuesta por las autoridades y en 177 casos de la aprobación de una ley o un tratado. En 
materia constitucional, la respuesta ha sido positiva en 164 casos y negativa en 55. En materia legislativa y con relación a convenios, la respuesta ha sido positiva en 98 casos y negativa en 79 . Un número de 202 iniciativas populares de reforma de la Constitución se han sometido a referéndum (24 fueron aprobadas y 178 rechazadas). Tomando en consideración el rechazo de las iniciativas populares y el apoyo a las contrapropuestas parlamentarias y el resultado de los referéndums obligatorios y facultativos como expresión de apoyo a los gobiernos, podría deducirse que los ciudadanos suizos han dado un amplio respaldo por lo general a las autoridades a lo largo de toda la historia.

La explicación de este fenómeno puede venir de varias razones. Durante los primeros años de democracia directa, cuatro de cada cinco votaciones se perdieron por el gobierno y el parlamento. A mediados del siglo xx, sin embargo, el número de éxitos y de fracasos era prácticamente igual y a partir de entonces la tendencia es más positiva para las autoridades. Una explicación vendría dada por la evolución en la composición del gobierno suizo a partir de la introducción de referéndum facultativo en la reforma constitucional de 1874 . Hasta 1891 el gobierno suizo estuvo formado exclusivamente por los miembros liberales del parlamento (los Radicales). Las decisiones parlamentarias tomadas exclusivamente por los Radicales empezaron a encontrar dificultades ya que sobre las mismas se solicitaba, por parte de las minorías - especialmente franco-parlantes y católicas conservadoras-, la celebración de referéndum. Esto forzó a que en 1891 se empezaran a incorporar representantes de otros grupos de la sociedad suiza, como católicos, agricultores y socialdemócratas. Por fin, en 1959 se introdujo la llamada "fórmula mágica» que exigía que la composición del gobierno debía corresponder a la fuerza relativa de los partidos en la Asamblea Federal, de manera que desde 1959 hasta 2003 el gobierno estuvo compuesto por dos representantes del PRD (Partido Radical Democrático), dos del PDC (Partido Demócrata Cristiano), dos del PS (Partido Socialista Suizo) y uno de la UDC (Unión Democrática del Centro) (Kaufmann et al., 2007: 54-56). Además, la fórmula de la contrapropuesta parlamentaria a una iniciativa popular y la posibilidad introducida en 1988 de dar un doble Sí a la iniciativa y a la contrapuesta, han dado a este instrumento como una de las opciones más exitosas, que además permite a la élite política reaccionar ante demandas formuladas en iniciativas populares y tener un diálogo institucionalizado con los ciudadanos durante la legislatura.

Por tanto, todo ello permite deducir que la introducción del referéndum facultativo, lejos de constituir un elemento de tensión y confrontación entre la voluntad ciudadana y la voluntad parlamentaria, ha servido para acercar ambas voluntades. Como demuestra la historia suiza, las políticas se han acercado más a las preferencias de los votantes conforme se han ampliado los instrumentos de participación directa. 
Pero además tampoco puede afirmarse con rotundidad que el referéndum sea un instrumento de participación política exclusivamente diseñado de abajo arriba (botton-up direct democratic instruments). Tanto la iniciativa popular como el referéndum facultativo exigen la recogida de un número de firmas. Por tanto, en principio, es un instrumento de participación política diseñado de abajo arriba. No obstante, la experiencia práctica demuestra que estos instrumentos no van en contra de los partidos políticos ni los partidos políticos están en contra de ellos (Morel, 1993: 225-244). En concreto, de la experiencia en los cantones suizos, Ladner y Brändle demostraron que frente a la tesis extendida de que la democracia directa debilitaba a los partidos políticos, la utilización del referéndum los convierte en estructuras más fuertes y profesionalizadas (Ladner y Brändle, 1999: 283-302). Además de que es un instrumento empleado por los partidos políticos y, fundamentalmente, por los partidos políticos de la oposición como arma contra el gobierno ${ }^{6}$. Como observa Serdült, desde 1990 puede observarse un declive de los referéndums obligatorios frente a un aumento de los referéndums facultativos. Esto indica la mayor confrontación política actual en Suiza. Durante los años noventa la gran coalición de los cuatro grandes partidos representados en el Ejecutivo comenzó a resquebrajarse y terminó rompiéndose después de las elecciones de 2003, cuando el Swiss People's Party se convirtió en el partido político más fuerte en el Consejo Nacional. De ahí que los referéndums facultativos hayan sido utilizados como arma política tanto por la izquierda como por la derecha para luchar contra la liberalización económica, la europeización o la globalización (Serdült, 2014: 79-80).

\section{3. ¿̇ES EL REFERÉNDUM UN INSTRUMENTO PARA LA MANIPULACIÓN DE LAS ÉLITES?}

Una de las principales críticas vertidas sobre el referéndum es el control del proceso ejercido por unas élites y con ello la posible manipulación de su resultado (the elite control syndrome). Y es cierto que a lo largo de la historia los gobernantes han convocado referéndums para legitimar sus decisiones po-

6 Desde 1874 hasta 1920, de los 44 referéndums celebrados, el 64 por ciento (28) fueron iniciados por partidos políticos en la oposición, que usaron este instrumento para consolidarse como partidos. Posteriormente, el grueso de los referéndums facultativos procede de fuerzas políticas enraizadas en la sociedad civil, aunque también el partido político en el gobierno necesita de vez en cuando utilizar este instrumento y demostrar que puede ganarlo. Véase Serdült y Welp (2012: 81-84, 87). 
líticas o ganar popularidad. O también que potentes grupos de presión han terminado ejerciendo influencia sobre el resultado final de referéndums.

En primer lugar, se trata esta de una crítica relativa, ya que igualmente es aplicable a los instrumentos de democracia representativa. Tal y como señala Stephen Tierney, "no hay una evidencia que demuestre que un referéndum, por definición, es más abierto a la manipulación de las élites que unas elecciones» (Tierney, 2012: 128). Además, los legisladores electos y los gobiernos también se enfrentan a la presión de los medios de comunicación, lobbies y otros grupos de interés en lo toma diaria de sus decisiones y, por supuesto, también influyen en ellas.

No se trata, por tanto, de un problema de principio que afecte exclusivamente a la figura del referéndum, sino más bien un problema referido a la práctica del referéndum en las democracias actuales y cuya solución o reducción del riesgo depende en gran medida del ordenamiento jurídico.

En general, resulta difícil reconocer que en Suiza las élites políticas o económicas tengan gran capacidad de manipulación. En primer lugar y fundamentalmente, al reconocerse a los ciudadanos la capacidad de iniciar un referéndum, o bien a través de la iniciativa popular, o bien a través del referéndum facultativo, el control de lo que se discute deja de estar en unas pocas élites y se encuentra al alcance de todos los ciudadanos. Es cierto que una vez convocado el referéndum el gobierno es el encargado de velar por el proceso e informar a los votantes, pudiendo incluso recomendar el sentido del voto. Pero su intervención está muy pautada y no se le permite ir más allá ni gastar fondos públicos a favor de una de las opciones (Decision of the Federal Supreme Court 114 Ia 427, 444; Decision of the Federal Supreme Court 114 Ia 427, 443).

Por otra parte, la regulación de la radio y la televisión y la exigencia de neutralidad en sus programas, prohibiendo, por ejemplo, el patrocinio de noticias o programas políticos, o prohibiendo los anuncios en radio o televisión a favor de una de las opciones por parte tanto de los partidos como de las organizaciones sociales, reduce también los márgenes para la manipulación informativa. Los comités y los partidos políticos solo pueden gastar su dinero en posteres, correo postal y anuncios en periódicos.

Aún reducido, como está, el margen de la manipulación, uno de los debates en el referéndum suizo es si los resultados del referéndum pueden comprarse con dinero. El debate comenzó con una obra de Gruner y Hertig en 1983 (Serdült, 2014: 84), concluyendo que los resultados de los referéndums pueden comprarse. Como reacción, algunos autores apuntaron casos en los que el dinero no había sido capaz de influir en el resultado final, argumentando que también pueden influir en el resultado la organización profesional y la infraestructura. Así, por ejemplo, el rechazo a la entrada en la UE en 1993, 
a pesar de que el mundo empresarial había gastado millones en la promoción (Kaufmann et al., 2007: 85-86). Recientes estudios señalan que sí hay un ámbito de influencia del dinero, especialmente cuando la cuestión es compleja, los resultados se prevén ajustados y la información de los ciudadanos es baja (Bernhard, 2012; Kriesi, 2012).

Reducir al máximo los posibles márgenes de manipulación en una campaña de referéndum exigiría en Suiza una obligación de revelar la identidad de los donantes y la cantidad de dinero gastada tanto por parte de los partidos políticos como por los grupos de la sociedad civil. No parece, sin embargo, que a corto plazo sean medidas que se vayan a adoptar en el sistema político suizo. A este respecto, los partidos políticos de izquierda, el Council of Europe's specialist body (GRECO), OSCE observadores para las elecciones nacionales de 2011 y Transparencia Internacional repetidamente piden una mayor regulación a este respecto. En cambio la derecha está más preocupada por limitar la intervención gubernamental en las campañas del referéndum. Ese era el objetivo de la iniciativa popular «Soberanía del pueblo en lugar de Propaganda del Gobierno", sometida a referéndum el 1 de junio de 2008, y patrocinada por un movimiento ciudadano de derechas llamado «Ciudadanos para ciudadanos». Iniciativa que fue rechazada por los 23 cantones y el 75,2\% de los votantes.

\section{EL DÉFICIT DELIBERATIVO EN EL REFERÉNDUM O EL MITO DEL CIUDADANO INCOMPETENTE}

Otra de las grandes críticas que suelen dirigirse al referéndum es que hay una tendencia a agregar prejuicios, en lugar de formar opiniones a través de la deliberación (the deliberation deficit) (Haskell, 2001: 11). No obstante, tampoco esta puede afirmarse que sea una crítica que afecte exclusivamente al referéndum. Igual que la crítica de la manipulación, esta también es una crítica aplicable a los procesos electorales (Goodin, 2008: 1) que pueden ser igual de complejos y exigir a los ciudadanos una opinión igualmente informada (Lutz, 2007: 630-631).

En el fondo esta crítica está directamente relacionada con la consideración de la incompetencia del ciudadano para tomar decisiones concretas. En los debates sobre la introducción del referéndum en las democracias esencialmente representativas con frecuencia se esgrime el argumento de que hay una categoría de ciudadanos (clase política) que está mejor preparada para decidir los asuntos públicos que otros (el ciudadano de a pie). Es el argumento de la incompetencia del ciudadano de a pie para tomar determinadas decisiones. También este argumento se utilizó en los siglos XIX y XX contra la extensión del sufragio masculino y los derechos de igualdad política para la mujer. Ac- 
tualmente se aduce la creciente complejidad de nuestras sociedades y la complejidad de las decisiones que han de adoptarse para considerar que los instrumentos de democracia directa o de democracia en general fueron concebidos para sociedades mucho menos complejas (Zolo, 1992: 13). Y el ciudadano de a pie no está preparado para dar la respuesta más adecuada. De hecho — - se señala - la incorrección de los resultados avalaría tal argumentación.

Göran Djupsund, profesor de Ciencias Políticas en Turku (Finlandia), escribió «que la democracia directa no siempre produce [...] buenos resultados. Podemos imaginar una situación en la cual hay una votación popular para decidir sobre asuntos que han lastimado a los ciudadanos. El resultado de encuestas de opinión pública aumenta las expectativas de la reintroducción de la pena de muerte, una reducción en el número de admitidos que han solicitado asilo político, un drástico recorte en los impuestos de los carburantes. Se podría esperar una expansión explosiva del sector público [...] mientras que, por otra parte, sectores de éste se reducirían a la nada, por ejemplo, las actividades de los museos, las orquestas municipales y los teatros de ópera» (Kaufmann et al., 2007: 69).

Precisamente la incorrección en los resultados de algunos referéndums en Suiza se utiliza como crítica al uso frecuente del referéndum. Así, por ejemplo, el tarde acceso a las Naciones Unidas, la tardía asunción del sufragio femenino o, más recientemente, la prohibición de construcción de minaretes.

Respecto a los resultados de las consultas celebradas en Suiza, señala Dardanelli (2011: 152) que en Suiza el referéndum obligatorio o facultativo actúa como «freno» —es más conservador - mientras la iniciativa popular actúa como «estímulo» —es más progresista—. El referéndum es «freno» porque actúa como veto al final de un proceso de toma de decisiones desde las instancias representativas. La iniciativa, en cambio, pone sobre la mesa cuestiones que van más allá de donde las instancias representativas quieren ir. Teniendo en cuenta que el porcentaje de consultas relativas a referéndums es mucho mayor que el que deriva de iniciativas populares, según este autor los instrumentos de democracia directa actúan mucho más como freno que como estímulo. Esto explicaría una integración internacional tardía (tarde acceso a las Naciones Unidas, no acceso al Espacio Económico Europeo o a la UE) o la tardía asunción del sufragio femenino o de la baja por maternidad.

En todo caso, si bien es verdad que las iniciativas populares ponen sobre la mesa aspectos "más progresistas", también es cierto que la mayoría de las iniciativas populares son votadas en contra. El 18 de mayo de 2003 se discutieron siete iniciativas populares sobre alquileres justos, seguros de salud asequibles, cuatro días sin coche al año, igualdad de derechos para los discapacitados, energía eléctrica no nuclear y renovación de la moratoria sobre la construcción de centrales de energía eléctrica. Las siete iniciativas fueron 
rechazadas por una amplia mayoría, tanto por los cantones como por los votantes. Y es que la mayoría de la sociedad suiza es conservadora, apoya a los partidos «burgueses» y son precavidos respecto a los cambios, especialmente si les cuesta dinero (Kaufmann et al., 2007: 21).

Más bien la iniciativa popular da a los ciudadanos la oportunidad de "pisar el pedal del acelerador a una reforma», mientras que el referéndum facultativo les da la oportunidad a los ciudadanos de pisar el pedal del freno (Kaufmann et al., 2007: 30). Pero juzgar los resultados de un referéndum por ser más o menos progresistas o conservadores es desconocer el significado de la democracia, que no ha de ser sino el reflejo de la sociedad que rige. En todo caso - y tal y como veremos más adelante- la discusión estaría en los límites que ha de ponerse a las decisiones democráticas. Pero estos límites - por ejemplo, los derechos humanos reconocidos internacionalmente- también pueden ser desconocidos por decisiones parlamentarias si, por ejemplo, partidos xenófobos obtienen mayorías suficientes en las elecciones.

Y si bien es cierto que son cada vez más complejos los problemas planteados en las sociedades actuales, también es cada vez mayor la demanda popular de una mayor participación en las decisiones políticas (cognitive mobilisation: Dalton, 1996; Inglehart, 1977) y la creciente desafección entre los votantes hacia las instituciones representativas. Tal y como señalan Mendelsohn y Parkin, se está produciendo un giro en las actitudes políticas de los ciudadanos, cuyo efecto es que los ciudadanos están más seguros de su habilidad en tomar decisiones políticas o menos seguros en la habilidad de los representantes electos para tomarlas (Mendelsohn y Parkin, 2001: 6). Ciertamente, con unos ciudadanos comprometidos cada vez más con la política a través de redes sociales, blogs, etc., la noción de que su participación en política debe estar circunscrita a las elecciones periódicamente convocadas resulta algo incongruente (Tierney, 2012: 11).

Es cierto que juzgar los referéndums por sus resultados más o menos progresistas es poco congruente con la noción misma de democracia. También es cierto que hoy en día el incremento de la complejidad se ve acompañado por una mayor demanda de participación y una mayor desconfianza de los ciudadanos hacia sus representantes políticos. Pero, a pesar de estas constataciones, todavía existe el riesgo real de que los ciudadanos adopten una decisión basada en prejuicios y no en argumentos. Para asegurar una opinión informada por parte de los electores es necesaria una regulación adecuada del proceso. De la experiencia suiza se desprende que los beneficios que pueden surgir de la democracia directa se materializan solo si los procedimientos están bien diseñados y garantizan información y transparencia a los ciudadanos.

En primer lugar, es importante que constitucional y/o legalmente se fijen con claridad los supuestos en los que la celebración del referéndum es 
obligatoria y los supuestos en los que los ciudadanos pueden someter una cuestión a referéndum. En este último caso es necesario prever constitucional y/o legislativamente el número de firmas necesarias, el plazo concedido (para la recogida de firmas, respuesta del gobierno, contrapropuesta parlamentaria y campaña de referéndum), la participación de los diferentes agentes en la campaña, requisitos de mayoría y quórums de participación, información para ciudadanos y consecuencias legales. Una de las garantías para una buena deliberación es la concesión de amplios plazos, no solo para la recogida de firmas, sino también, una vez recogidas las firmas, para la celebración del referéndum.

Ya hemos señalado que en Suiza el gobierno distribuye folletos de información oficial junto con el material electoral donde hace una síntesis de los argumentos a favor y en contra de la consulta. No obstante, los votantes suizos hacen uso de otros medios y fuentes para llegar a una decisión. Las secciones editoriales de la prensa escrita y las recomendaciones de los partidos constituyen una importante fuente de información para una parte de los ciudadanos. Incluso los votantes suizos en el extranjero cuentan, además de con el folleto de referencia, con acceso a ediciones extranjeras especiales de los principales diarios, se les envían cintas gratuitas de debates de radio y pueden ver páginas web especiales enfocadas a los referéndums. También pueden contar con un correo electrónico especial que les informa del debate del referéndum actual y de futuras votaciones. Pero tal y como demuestran las encuestas, el debate cara a cara con amigos y conocidos es la fuente más importante de información (Kaufmann et al., 2007: 77-79).

\section{5. ¿̇ES EL REFERÉNDUM UN INSTRUMENTO DE CONSOLIDACIÓN DE MAYORÍAS?}

Quizás la crítica más grave con la que se enfrenta el referéndum es la que considera que es un instrumento que consolida mayorías, sin tener en cuenta las minorías ni los intereses individuales (the majoritarian danger) (Wvortrup, 2002: 158; Madison, 2014: 35-41). En el peligro que aquí se plantea cabría distinguir dos problemas. Por una parte, es cierto que en el referéndum, y no en la toma de decisiones parlamentarias, la opinión de los electores se expresa aceptando o rechazando los proyectos que se les someten a votación sin que haya un proceso previo de negociación para la toma de decisiones. A este respecto, el peligro del referéndum sería la ausencia de una posible negociación para el acercamiento de posiciones. Por otra parte, tanto en el referéndum como en la toma de decisiones parlamentarias, la democracia impone la regla de la mayoría, lo cual plantea el problema de las minorías y su posible desprotección. Veamos si estos problemas se resuelven o no en la experiencia suiza. 


\section{El referéndum como instrumento de negociación e integración de minorías}

Desde la perspectiva de la negociación previa a la toma de decisiones, la experiencia suiza demuestra que el referéndum, lejos de ser un instrumento de mayorías, ha funcionado como un instrumento de integración de minorías. Y es precisamente la influencia del referéndum, y no tanto de la fórmula electoral, la que ha determinado la calificación de la democracia suiza como consensual ${ }^{7}$.

En su clásico estudio comparativo de democracias consensuales y mayoritarias, Lijphart (2012: 45-52) usa a Suiza como ejemplo de democracia consensual. No obstante, no siempre fue así. Hasta 1874 los Radicales (un partido liberal cuya base fundamental es el voto urbano protestante) dominaban el parlamento federal y monopolizaban el poder ejecutivo. No existía ninguna compartición del poder ni ningún consenso en las decisiones. Esto comenzó a cambiar con la introducción del referéndum facultativo en la reforma constitucional de 1874. Las decisiones parlamentarias tomadas exclusivamente por los Radicales empezaron a encontrar dificultades ya que sobre las mismas se solicitaba, por parte de las minorías - especialmente franco-parlantes y católicas conservadoras-, la celebración de referéndum. Esto forzó a que en 1891 se introdujera el primero de los aspectos característicos de la democracia consensual suiza: la repartición del poder en el ejecutivo ${ }^{8}$. En ese año fue elegido un miembro conservador católico en el Consejo Federal, aunque los Radicales seguían teniendo el control total del parlamento. La integración de otros partidos en el Consejo Federal se fue produciendo, de manera que desde 1959 hasta el comienzo del siglo Xxi se adoptó la así llamada "fórmula mágica» y que suponía la representación en el Consejo Federal de todos los partidos en proporción a su representación parlamentaria, lo cual debía suponer también una representación equitativa de la diversas regiones y comunidades lingüísticas?.

7 Esto no excluye que junto con los instrumentos de la democracia directa existan otros factores que puedan haber incidido en la democracia consociativa suiza. Así lo señala Papadopoulos (2001: 46-48).

8 Hay que recordar que en el sistema de gobierno suizo los ministros son elegidos individualmente por el parlamento y no responden ante él, constituyendo una forma semipresidencialista de gobierno.

9 No más de un ministro debe proceder de un mismo cantón y al menos dos de siete deben ser no alemano-parlantes. Sobre la influencia del referéndum en el inicio de la democracia consociativa véase Dardanelli (2011: 150, 153-154). Sobre la influencia del 
Curiosamente el papel de referéndum legislativo fundamentalmente como integrador de minorías reduce la importancia del sistema electoral respecto al carácter consensual de la democracia. Y es que teóricamente mientras las democracias con sistemas electorales mayoritarios son de corte menos consensual, las democracias con sistemas electorales proporcionales tienden a un mayor consenso. Sin embargo, se relativiza el efecto del sistema electoral en el caso de Suiza. El sistema electoral para el Consejo Nacional suizo pasó de ser mayoritario a ser proporcional gracias a un referéndum celebrado en 1918. A pesar de ello, estudios empíricos realizados en los cantones suizos señalan que la naturaleza consensual de la democracia no depende en Suiza de la fórmula electoral. En algunos cantones donde el parlamento es elegido por un sistema mayoritario y altas barreras electorales, el referéndum legislativo y la iniciativa no son empleados con mayor frecuencia que en los cantones con un sistema electoral puramente proporcional y bajas barreras electorales (Linder y Vatter, 2001: 111-112).

Por otra parte, también el referéndum y la eventual amenaza de su convocatoria frente a decisiones legislativas han promovido en la democracia suiza un amplio sistema de consultas preparlamentarias. Cualquier propuesta de nueva legislación es debatida antes de su consideración parlamentaria por un amplio sector institucional y social (partidos, cantones y grupos de interés). Estas consultas tienen como principal objetivo el asegurar que todos los intereses afectados por la nueva regulación - y especialmente los actores «capaces de presentar una amenaza creíble de referéndum» (Kriese y Trechsel, 2008: 115) - tengan la oportunidad de dar su opinión y ser oídos. Se trata de un rasgo propio del sistema político suizo que le ha supuesto tener un proceso más largo de toma de decisiones parlamentarias respecto de la mayoría de las democracias europeas, sin que ello suponga una reducción significativa del grado de conflicto en la fase parlamentaria de la legislación (Papadopoulos, 2001: 41-43).

Por último, cuando las iniciativas populares ya se han puesto en marcha se abre un proceso de negociación ex post que puede incorporar parcialmente las demandas o bien directamente en un contraproyecto parlamentario de reforma constitucional o bien indirectamente a través de una modificación legislativa. De ahí que, a pesar del bajo número de iniciativas populares aprobadas en referéndum, el 50 por ciento de ellas han dejado alguna marca en la legislación federal (Serdült, 2014: 86; Papadopoulos, 2001: 43-46).

referéndum facultativo en la formación de gobiernos de coalición, véase Papadopoulos (2001: 38-41). 
En definitiva, la experiencia suiza demuestra que el uso del referéndum, lejos de constituir un peligro por la ausencia de negociación que, sin embargo, implica la toma de decisión parlamentaria, propicia una democracia más consensual y abierta al diálogo entre los diferentes partidos políticos y de estos con las organizaciones sociales.

\section{La regla de la mayoría y los mecanismos de protección de minorías}

El principio democrático se traduce en el momento de organización del poder en la regla de la mayoría. Las decisiones son tomadas por la mayoría, mientras la minoría, aunque puede participar con más o menos intensidad en el proceso de toma de decisión, no determina la decisión final. El problema de la protección de los intereses de la minoría afecta no solo a las decisiones que se toman a través del referéndum, sino también a todas las decisiones parlamentarias. A este respecto, la experiencia suiza muestra que históricamente se ha tratado de proteger los intereses de las minorías lingüísticas y religiosas a través del federalismo, aunque hoy en día están realmente en peligro los intereses de las minorías no concentradas geográficamente.

\section{A) El federalismo como protección de minorías concentradas geográficamente}

Junto con Estados Unidos, Canadá o Alemania, Suiza es uno de los clásicos Estados federales del mundo. Precisamente esa estructura federal ha servido históricamente como instrumento de protección de minorías concentradas geográficamente en los cantones, especialmente las minorías conservadoras y católicas de los cantones rurales y pequeños del centro de Suiza.

Por una parte, ya hemos visto que toda reforma constitucional exige que sea aprobada por referéndum no solo del pueblo en su conjunto sino también de los cantones. La exigencia de la doble mayoría nació como un compromiso entre los cantones protestantes y los cantones católicos en la Constitución de 1848 y pretendía proteger los intereses de los cantones más pequeños y rurales del centro de Suiza. De esta manera se evita, por ejemplo, que ninguna reforma constitucional pueda ser aprobada por los cinco grandes cantones y semi-cantones del noroeste más industrializados. Este peso específico con el que cuentan los cantones más conservadores para aprobar la reforma de la Constitución en referéndum explica, por ejemplo, las resistencias a la centralización competencial, el retraso en la formación de un Estado de bienestar en Suiza o la oposición de la apertura de Suiza en sus relaciones exteriores (Linder y Vatter, 2001: 97-99; Obinger, 1998: 257).

Hay que subrayar que la exigencia de doble mayoría en referéndum para la reforma constitucional está cada vez más en entredicho. La disparidad en el 
tamaño de la población en los cantones ha aumentado a lo largo del tiempo, con una cada vez mayor concentración de la población en los más industrializados. Un voto en el cantón de Appenzell Rodas Interiores pesa más de 40 veces que un voto en el cantón de Zúrich. De esta manera, una pequeña fracción del electorado (entre el 20-25 por ciento) en los pequeños Cantones puede bloquear a todo el país (Linder, 2007: 110). Esto, además, aumenta el riesgo de posible colisión de las dos mayorías requeridas. Entre 1848 y 1999 ha habido diez colisiones en la doble mayoría exigida para toda reforma constitucional, seis de las cuales solo en los últimos treinta años.

Otra estructura federal que ha beneficiado históricamente a los cantones pequeños y rurales ha sido el Consejo de Estados ${ }^{10}$. No porque este funcione como una cámara territorial, sino porque su sistema electoral da ventaja a los partidos de corte católico y conservador haciendo que esta cámara sea menos propicia a los cambios (Linder y Vatter, 2001: 99-102).

Por tanto, estructuras federales como la exigencia de la doble mayoría para la reforma constitucional o el Consejo de Estados ha servido históricamente de instrumentos de protección de las minorías concentradas geográficamente en los cantones más pequeños. Pero que con el tiempo pierden sentido. La inmigración ha diluido la original homogeneidad étnica y religiosa de algunos cantones y que se pretendía proteger a través del federalismo. El incremento en la diferencia poblacional de los cantones y la progresiva erosión en las diferencias entre ellos hacen que esta protección dispensada a determinados cantones pueda chocar con los principios democráticos (Dardanelli, 2011: 158).

Más allá de eso, realmente las estructuras federales no han servido desde una perspectiva general para la integración de los intereses cantonales en la decisión federal. En el caso de Suiza, esta integración ha venido de la mano del referéndum. La integración de los intereses cantonales en la decisión federal está en directa relación con la capacidad de forzar la convocatoria de un referéndum o su capacidad de movilización social en un referéndum, al igual que ocurre con el poder de influencia de otros grupos de interés.

10 El Consejo de los Estados es el Senado suizo y está constituido por 46 miembros. Veinte de los cantones, independientemente de su tamaño, cuentan con el mismo número de representantes (dos cada uno), mientras que por razones históricas seis cantones (Basilea-Ciudad, Basilea-Campiña, Alto Unterwald, Bajo Unterwald, Appenzell Rodas Exteriores y Appenzell Rodas Interiores) cuentan con un único representante. Está en una posición de igualdad respecto al Consejo Nacional, de manera que si hay discrepancias respeto a una ley entre las dos cámaras se pone en marcha el procedimiento de "resolución de conflictos» que puede terminar en una propuesta de compromiso que deberán votar en ambos Consejos. 
A este respecto, al posibilitar que ocho cantones puedan forzar la convocatoria de un referéndum sobre una ley aprobada en Parlamento, se fuerza también a tratar de integrar sus intereses en la normativa estatal. Aunque este referéndum solo requerirá para ser definitivamente aprobado por la mayoría de votos ciudadanos. No obstante, solo en contadas ocasiones se ha puesto en marcha el referéndum cantonal. Desde su introducción en 1874 hubo de transcurrir más de un siglo (en 1981) para que un cantón se planteara presentarlo. Fue el cantón de Tesino para oponerse a una modificación en el derecho penal, aunque finalmente no obtuvo el necesario respaldo para presentarlo. No sería hasta el año 2004 cuando se votaría un referéndum de iniciativa cantonal, firmado por once cantones en contra de legislación federal tributaria que bajaba los impuestos cantonales. El 16 de mayo de 2004, el 67,2 por ciento de los votantes rechazo la propuesta legislativa.

A pesar de la capacidad de los cantones de forzar la celebración de un referéndum, no parece que tengan, sin embargo, gran capacidad de movilización. De ahí que muchos estudios han concluido que los cantones no tienen una gran capacidad de influencia en la decisión federal en materia de política económica o social en comparación con otros grupos de interés. $\mathrm{Y}$, en todo caso, resultan más influyentes los cantones con fuerte estructura administrativa frente a los que cuentan con estructuras pequeñas y débiles (Linder y Vatter, 2001: 102-103).

\section{B) La inmigración y el problema actual de la protección de minorías no concen- tradas geográficamente}

El reconocimiento de la iniciativa popular da oportunidad a las minorías de participar e incorporar cuestiones en la agenda política del país. En este sentido, tiene el efecto de desradicalizar los movimientos sociales ya que en la práctica sus demandas se moderan y aceptan las contrapropuestas procedentes de las autoridades (Papadopoulos, 2001: 45).

Sin embargo, el hecho de que no se exijan mayorías cualificadas para aprobar por referéndum reformas constitucionales y no haya límites materiales a las iniciativas populares de reforma constitucional pone en peligro las minorías que no están concentradas geográficamente y, concretamente, a los inmigrantes. Un peligro que puede nacer también de la iniciativa de reforma constitucional proveniente de la Asamblea Federal, ya que tampoco tiene cláusulas de intangibilidad ni su aprobación exige de mayorías cualificadas en el procedimiento legislativo ni en la aprobación final por referéndum del pueblo y los cantones. Aquí nos centraremos en los casos que recientemente han planteado el peligro de la protección de minorías en el ámbito del referéndum y las iniciativas populares. 
Un buen ejemplo de este peligro lo representó la iniciativa popular aprobada en referéndum el 29 de noviembre de 2009 que incorporó la prohibición de construcción de minaretes en la Constitución (art. 72, sec. 3). Opositores a esta iniciativa advirtieron que violaba la libertad religiosa, garantizada en la Constitución Federal suiza (art. 15), y en el Convenio Europeo de Derechos Humanos (art. 9), del cual Suiza es parte. También se criticó que la prohibición de construir minaretes infringía la prohibición contra la discriminación garantizada en la Constitución Federal suiza (art. 8), ya que se dirigía exclusivamente a la población musulmana de Suiza. También organismos internacionales expresaron su preocupación y su oposición contra esta iniciativa y advirtieron que violaba leyes internacionales reconocidas en Suiza. A pesar de la oposición del gobierno, el parlamento, grupos de derechos humanos, iglesias y partidos liberales, la iniciativa ganó con un $57,5 \%$ de los votos. El resultado de esta votación fue vinculante y no hubo ocasión de revisión judicial. En 2009, el Tribunal Supremo rechazó dos casos contra la nueva previsión constitucional, ya que los demandantes no habían demostrado una concreta afectación de sus derechos constitucionales. También la Corte Europea de Derechos Humanos rechazó dos peticiones contra la prohibición de minaretes en 2011 (Josi, 2014: 12-13).

También se han incorporado otras enmiendas en la Constitución referidas a la inmigración y derivadas de su aprobación en referéndum. El 28 de noviembre de 2010 se aprobó en referéndum una iniciativa popular de reforma constitucional para la expulsión de los criminales extranjeros (art. 121, sec. 3). No obstante, el Tribunal Supremo decidió en octubre de 2012 que esta disposición no era directamente aplicable. De ahí que en la misma materia siga estando en la agenda una nueva iniciativa popular titulada «Para una efectiva expulsión de los criminales extranjeros» que será objeto de votación probablemente en 2016 (Gonin, 2014: 6; Raaflaub, 2015). Desde las fuerzas ecologistas se ha lanzado una iniciativa dirigida a parar la sobrepoblación para una conservación sostenible de los recursos naturales. Se pretende, entre otras cosas, restringir la inmigración sobre el territorio suizo para preservar la diversidad ecológica del país. Cuando se escriben estas líneas todavía no se ha votado. Por otra parte, el 9 de febrero de 2014 se aprobó en referéndum una iniciativa dirigida "Contra la inmigración masiva».

Este tipo de iniciativas ha llevado recientemente a valorar la necesidad de poner límites al uso del referéndum y, en concreto, a tratar de reducir los posibles conflictos entre los derechos humanos y la democracia en Suiza. Es cierto que se han sometido a referéndum en el pasado algunas iniciativas que en algún sentido resultaban incompatibles con los derechos humanos, pero la aprobación de este tipo de iniciativas por referéndum es una tendencia actual (Josi, 2014: 17). 
Por una parte, se sugiere introducir límites materiales a la iniciativa popular de reforma constitucional. Autores como Benoît sugieren prohibir cualquier iniciativa de reforma constitucional que viole el Convenio Europeo de Derechos Humanos (Gonin, 2014: 8). No obstante, tal y como ha puesto de relieve la doctrina, dicha limitación se encuentra con diversos problemas, ya que se trataría de un límite a la democracia que introduciría incertidumbre en el sistema legal suizo dado el carácter dinámico $\mathrm{y}$, en muchas ocasiones, indefinido, de los derechos humanos (Gonin, 2014: 8 ss). De hecho, está generalmente aceptado que las normas internacionales de ius cogens incluyen la prohibición de crímenes contra la humanidad, genocidio, esclavitud y tortura. No obstante, por ejemplo en el caso de los minaretes, es discutible si la libertad religiosa como derecho afectado haya emergido como ius cogens (JOSI, 2014: 12). Daniel Vischer, miembro de la comisión de política institucional del Consejo Nacional, sugirió ampliar el margen de restricciones materiales de las iniciativas populares a los derechos fundamentales. Se ampliaría así la capacidad del Parlamento de declarar inválida una iniciativa popular que se presentara (Josi, 2014: 18).

Por otra parte, se sugiere introducir nuevos mecanismos de control de las iniciativas. Simonetta Sommaruga, ministra federal del Departamento de Policía y Justicia, sugiere un control previo del contenido de la iniciativa por la Administración federal, similar a un dictamen consultivo. La Administración federal haría una evaluación sobre la compatibilidad de la iniciativa con el derecho internacional, pero sin la posibilidad de declararlo inválido. Esta evaluación permitiría a los promotores de la iniciativa modificar el texto original o mantener la propuesta original. En cualquier caso, los resultados de la evaluación se publicarían y se tendrían que publicar en los formularios de recogida de firmas (Josi, 2014: 18).

Por su parte, Andreas Auer, profesor de derecho constitucional en la Universidad de Zúrich y director del Centro para la Democracia en Aarau, está de acuerdo con que Suiza debe desarrollar formas de evitar iniciativas populares que violen los derechos humanos internacionalmente garantizados. No obstante, considera que si bien el gobierno o el parlamento podrían examinar la propuesta, la decisión final de realizar el referéndum debería estar en manos de un tribunal.

En este sentido cabría plantear la ampliación de la competencia del Tribunal Supremo suizo para permitir el control judicial de las iniciativas populares (Josi, 2014: 24). Como resultado de la falta de una Corte constitucional como tal, donde haya un control abstracto de las leyes, el resultado del referéndum constitucional es vinculante. La Constitución suiza establece en el artículo 191 que el Tribunal Supremo y las demás autoridades están obligadas a aplicar la legislación federal y los Tratados Internacionales. Por tanto, el Tri- 
bunal Supremo no es competente para derogar leyes federales aun en el caso de que encuentre incompatibilidades con la Constitución. Tan solo podrá anular concretos actos administrativos como inconstitucionales, sin que la ley que origine dicho acto pueda ser invalidada. Evidentemente tampoco podrá entrar a juzgar la constitucionalidad en abstracto de una reforma constitucional, aunque la misma entre en clara contradicción con derechos constitucionales. Por ello, parecería conveniente que el Tribunal Supremo pudiera juzgar la constitucionalidad de una iniciativa popular, antes de que esta se someta a referéndum.

Subrayemos, no obstante, que el actual debate suscitado en Suiza, aunque circunscrito a las iniciativas populares, pone sobre la mesa una cuestión que no solo afecta a los instrumentos de la democracia directa, sino también a las decisiones parlamentarias. En definitiva, de lo que se está hablando actualmente en Suiza es de si cabe establecer límites a la democracia, cuáles podrían ser estos límites y quién sería la instancia más adecuada para controlarlos.

\section{UN BREVE APUNTE SOBRE LOS EFECTOS ECONÓMICOS DEL REFERÉNDUM EN SUIZA}

No podemos terminar el análisis de la experiencia del referéndum en Suiza desde la perspectiva de las críticas a este instrumento sin referirnos a aquellas críticas que han vinculado la democracia directa con un mayor gasto y un empeoramiento en la situación económica.

Pues bien, no hay resultados concluyentes sobre los efectos que tiene el referéndum respecto al crecimiento económico y la fiscalidad en Suiza. La mayoría de los estudios empíricos sobre los cantones evidencia que el referéndum tiene efectos positivos sobre la economía. Gebhard Kirchgässner, Lars Feld y Marcel Savioz concluyen que el crecimiento del gasto público es menor en las ciudades que hacen más uso del referéndum. Werner Pommerehne y Hannelore Weck-Hannemann demostraron que se tenía una mejor disposición para el pago de impuestos y había menos evasión fiscal en los cantones con más derechos de participación política de los ciudadanos. Feld y Savioz presentaron evidencias empíricas de un mejor resultado económico en los cantones con mayor peso de instrumentos de democracia directa. Estos estudios se contrastan con otros de economistas suizos que señalan que el referéndum es la principal causa del lento crecimiento económico en Suiza (Linder y Vatter, 2001: 114-115).

En cualquier caso, los resultados de referéndums celebrados desmienten la premisa de que los votantes no son capaces de equilibrar los costes (a corto plazo) contra los beneficios (a largo plazo) cuando se trata de finanzas públicas. En el referéndum del 7 de marzo de 1993, el 54,5 por ciento de 
los votantes aprobaron un aumento en el precio de la gasolina y del diésel. Cinco años más tarde, más del 57 por ciento votaron a favor de introducir un impuesto para vehículos pesados en relación con las distancias recorridas, pensado para aumentar el coste del transporte de mercancías por carretera. En 1993, dos tercios de los votantes estuvieron de acuerdo con la introducción del IVA nacional y en utilizarlo para un futuro aumento de las pensiones de jubilación (Kaufmann et al., 2007: 84).

\section{ALGUNAS CONCLUSIONES}

Las principales disfuncionalidades denunciadas por la doctrina respecto a la institución del referéndum las sintetizó Tierney en tres grandes grupos (Tierney, 2012: 23). En primer lugar, el control del proceso ejercido por unas élites y con ello la posible manipulación de su resultado (the elite control syndrome). En segundo lugar, se señala que hay una tendencia en los procesos de referéndum a agregar prejuicios, en lugar de formar opiniones a través de la deliberación (the deliberation deficit). Y en tercer lugar, se considera que los referéndums consolidan mayorías, sin tener en cuenta las minorías ni los intereses individuales (the majoritarian danger). Aunque de una menor entidad, también es habitual entre las críticas al referéndum señalar que la escasa participación en referéndums hace perder su legitimidad democrática, que suponen una confrontación de voluntades y legitimidades - la parlamentaria y la popular- y con ello un debilitamiento de la democracia representativa o que el uso del referéndum tiene efectos económicos negativos.

A lo largo de este artículo hemos analizado la regulación del referéndum y su práctica política en el país del mundo que más experiencia tiene al respecto, Suiza. Este análisis permite constatar que las grandes críticas vertidas sobre la institución de referéndum son más bien problemas referidos a la práctica del referéndum en las democracias actuales y no tanto problemas de principio. Es decir, que los méritos o deméritos democráticos del referéndum dependen en gran medida de la regulación del mismo y que, por tanto, cabría paliar cada uno de los problemas detectados en la práctica a través del derecho y de una regulación adecuada del mismo (Tierney, 2014: 2).

La representación política es imprescindible en las democracias contemporáneas. Y lo que hace imprescindible la representación es la división del trabajo. En este sentido, tal y como lo concibieron ya el abate Sieyès y a través del pensamiento weberiano autores como Alf Ross (Cebrián, 2013: 43), la representación es la traducción política del principio de división del trabajo. Pero tal y como demuestra la experiencia suiza, que es un país con una democracia representativa donde - recuerdo- el 93 por ciento de las leyes apro- 
badas en su Parlamento no son sometidas a referéndum, es que este principio no excluye abrir cauces de participación de los ciudadanos que vayan más allá de las elecciones cada cuatro años y supongan un medio de control de los ciudadanos hacia sus representantes políticos. Cauces que se estructuran fundamentalmente a través de la iniciativa popular y el referéndum.

Esta realidad no constituye un choque de legitimidades ni un debilitamiento de la democracia representativa. Los representantes políticos dejan de percibir a los ciudadanos como outsiders del sistema y a los instrumentos de democracia directa como instrumentos contra ellos. De hecho, hemos observado que los instrumentos de democracia directa se insertan en el esquema institucional de la democracia representativa y son también empleados por los partidos políticos envueltos en los procesos de decisión institucional. El resultado es que la voluntad de los representantes tiende a acercarse a la de los representados y los partidos desarrollan unas estructuras potentes que les permiten constituirse en verdaderos vehículos de formación de la voluntad popular.

Tampoco el referéndum es en Suiza un instrumento que haya servido de consolidación de mayorías y desprotección de minorías. Desde la perspectiva de la negociación previa a la toma de decisiones, la experiencia suiza demuestra que es precisamente la influencia del referéndum, y no tanto de la fórmula electoral, la que ha determinado la calificación de la democracia suiza como consensual. Por otra parte, la regla de la mayoría, vigente tanto en el referéndum como en las decisiones parlamentarias, puede hacer peligrar la protección de determinadas minorías. Suiza utilizó la fórmula federalista para proteger las minorías lingüísticas y religiosas, pero hoy están en peligro los derechos de minorías no concentradas geográficamente, como los inmigrantes. No obstante, no es este un problema del referéndum, sino también de las decisiones parlamentarias, y pone sobre la mesa el debate acerca de los límites de la democracia.

Frente al riesgo de convertir el referéndum en instrumento de manipulación por las élites, Suiza ha optado por el reconocimiento de que la iniciativa parta de los propios ciudadanos a través de la recogida de un número de firmas, tanto para convocar un referéndum legislativo como para proponer una reforma constitucional. Es cierto que excluye la iniciativa de las autoridades para convocar un referéndum legislativo, pero esta exclusión no significa, como hemos visto, que las autoridades no puedan plantearlo, aunque lo hacen a través de los partidos políticos. Lo que parece conveniente es que la iniciativa del referéndum no dependa exclusivamente de la discrecionalidad del gobierno, ya que cuando los gobiernos controlan el referéndum, ellos tienden a usarlo solo cuando esperan ganar. Si no existe monopolio gubernamental en la convocatoria del referéndum, tampoco existe el peligro de que solo se 
convoque cuando esté la victoria asegurada. Es cierto que en Suiza el gobierno es el encargado de velar por el proceso e informar a los votantes, pero su intervención está muy pautada. También la regulación de los medios de comunicación reduce los márgenes de manipulación por parte de los lobbies. Sin embargo, tal y como hemos señalado, los márgenes de manipulación todavía existen cuando la cuestión es compleja, los resultados se prevén ajustados y la información de los ciudadanos es baja. Reducir al máximo los posibles márgenes de manipulación en una campaña de referéndum exigiría en Suiza una obligación de revelar la identidad de los donantes y la cantidad de dinero gastada tanto por parte de los partidos políticos como por parte de los grupos de la sociedad civil.

Por otra parte, para garantizar un proceso deliberativo y no la simple acumulación de prejuicios en un referéndum es necesaria una regulación adecuada. De la experiencia suiza se desprende que los beneficios que pueden surgir de la democracia directa se materializan solo si los procedimientos están bien diseñados y garantizan información y transparencia a los ciudadanos. A partir de ahí, juzgar los resultados de un referéndum por ser más o menos progresistas o conservadores es desconocer el significado de la democracia, que no ha de ser sino el reflejo de la sociedad que rige.

Eso sí. Dos son principalmente los precios que se ha de pagar en sistemas con fuertes instrumentos de democracia directa. Por una parte, los largos procesos para la toma de decisiones. Por otra parte, la escasa participación en la mayoría de las consultas. Suiza es un claro ejemplo en ambos aspectos. Un rasgo propio del sistema político suizo es que tiene uno de los procesos más largos en la toma de decisiones respecto a la mayoría de las democracias europeas. También la participación en las consultas es baja, ya que con carácter general la participación en referéndums en Suiza está por debajo del 50 por ciento. Ciertamente es un signo de salud democrática una alta participación ciudadana en la toma de decisiones. Pero, tal y como demuestra la experiencia suiza, esto no permite afirmar que la escasa participación ciudadana sea un signo de falta de salud democrática. Solo sería así si esa falta de participación respondiera a una general desafección con el sistema democrático. Pero, a tenor del grado de satisfacción mostrado por los ciudadanos suizos con su sistema, no parece que la baja participación se deba a una desafección con el sistema.

La democracia representativa es imprescindible en las democracias contemporáneas. Pero ello no significa que no deba ser completada con instrumentos que, como el referéndum, permitan un acercamiento de las políticas a la voluntad del pueblo y un mayor control democrático de los representantes políticos. Las principales críticas vertidas sobre el referéndum no son problemas de principio, sino referidos a la práctica del mismo, y que cabría paliar a través de su regulación adecuada. La experiencia suiza es un claro ejemplo. 


\section{Fuentes documentales}

Base de datos sobre los referéndums en todo el mundo: Centre for Research on Direct Democracy (c2d), Universidad de Zúrich. Disponible en: http://www.c2d.ch/votes.php?table=votes (consultada el 28 de diciembre de 2015).

Base de datos sobre los referéndums en el ámbito federal suizo: Cancillería Federal Suiza, Sección de derechos políticos. Disponible en: http://www.admin.ch/ch/d/pore/rf/ ref_2_2_3_1.html\# (consultada el 13 de mayo de 2015).

Constitución Suiza. Disponible en: https://www.admin.ch/ch/e/rs/1/101.en.pdf (consultada el 20 de mayo de 2015).

Ley Federal sobre Derechos Políticos de 17 de diciembre de 1976. Disponible en: https:// www.admin.ch/ch/e/rs/c161_1.html (consultada el 28 de abril de 2015).

Ley Federal sobre Radio y Televisión, aprobada el 24 de marzo de 2006. Disponible en: https://www.admin.ch/opc/en/classified-compilation/20001794/index.html (consultada el 5 de mayo de 2015).

Ley Federal, de 19 de diciembre de 1975, sobre los derechos políticos de los ciudadanos suizos que viven o se encuentran en el extranjero. Disponible en: https:/www.admin.ch/opc/ fr/classified-compilation/19750378/index.html (consultada el 5 de mayo de 2015).

Raaflaub, C. (2015), ¿Voluntad popular al pie de la letra?, SwissInfo, 15-4-2015. Disponible en: http://www.swissinfo.ch/spa/politica/iniciativa-de-ejecuci\%C3\%B3n---voluntadpopular-al-pie-de-la-letra-/41379276 (consultada el 28 de diciembre de 2015).

\section{Bibliografía}

Bernhard, L. (2012). Campaign Strategy in Direct Democracy. Nueva York: Palgrave Macmillan.

Cebrián Zazurca, E. (2013). Sobre la democracia representativa. Un análisis de sus capacidades e insuficiencias. Zaragoza: Prensas de la Universidad de Zaragoza.

Dalton, R. J. (1996). Citizen Politics in Western Democracies: Public Opinion and Political Parties in the US, UK, Germany and France. 2a ed. Londres: Chatham House.

Dardanelli, P. (2011). The Emergence and Evolution of Democracy in Switzerland. En M. F. T. Malone (ed.). Achieving Democracy: Democratization in Theory and Practice. Nueva York, Londres: Continuum.

Gonin, L. (2014). Swiss direct democracy in a globalized world: a need for change? Ponencia presentada y publicada en The IXth World Congress of Constitutional Law 2014 sobre "Constitutional Challenges: Global and Local», celebrado en Oslo del 16 al 20 de junio de 2014. Disponible en: https:/www.jus.uio.no/english/research/news-and-events/ events/conferences/2014/wccl-cmdc/wccl/papers/workshop16.html

Goodin, R. (2008). Innovating Democracy: Democratic Theory and Practice after the Deliberative Turn. Oxford: Oxford University Press.

Hamilton, A., Madison, J. y Jay, J.(2014). El Federalista. México, DF: Fondo de Cultura Económica.

Haskell, J. (2001). Direct Democracy or Representative Government? Dispelling the Populist Myth. Boulder, CO: Westwiew Press. 
Inglehart, R. (1977). The Silent Revolution: Changing Values and Political Styles Among Western Publics. Princeton: Princeton University Press.

Josi, C. (2014). Direct democracy: what if there is a conflict between the will of the people and fundamental rights? A comparative analysis between Switzerland and California. Ponencia presentada y publicada en The IXth World Congress of Constitutional Law 2014 sobre "Constitutional Challenges: Global and Local», celebrado en Oslo del 16 al 20 de junio de 2014. Disponible en: https:/www.jus.uio.no/english/research/news-andevents/events/conferences/2014/wccl-cmdc/wccl/papers/workshop16.html.

Kaufmann, B., Büchi, R. y Braun, N. (2007). Guía de la democracia directa. En Suiza y más allá. Berna: Initiative \& Referendum Institute Europe.

Kriesi, H. (2005). Direct Democratic Choice. The Swiss Experience. Lanham, M. D.: Lexington Books.

- (2012). Political Communication in Direct Democratic Campaigns: Enlightening or Manipulating? Nueva York: Palgrave Macmillan.

Kriesi, H. y Trechsel, A. H. (2008). The Politics of Switzerland: Continuity and Change in a Consensus Democracy. Cambridge: Cambridge University Press.

Ladner, A. y Brändle, M. (1999). Does Direct Democracy Matter for Political Parties? An Empirical Test in the Swiss Cantons. Party Politics 5 (3), 283-302. Disponible en: http:// dx.doi.org/10.1177/1354068899005003002.

Lijphart, A. (2012). Modelos de democracia: Formas de gobierno y resultados en 36 países. Barcelona: Ariel.

Linder, W. (2007). Direct Democracy. En U. Klöti et al. (eds.). Handbook of Swiss Politics. $2^{a}$ ed. revisada. Zürich: Neue Zürcher Zeitung Publishing.

Linder, W. y Vatter, A. (2001). Institutions and Outcomes of Swiss Federalism: The Role of the Cantons in Swiss Politics. En J. Lane (ed.). The Swiss Labyrinth: Institutions, Outcomes and Redesign. Londres-Portland: Frank Cass.

Lüchinger, S., Rosinger, M., y Stutzer, A. (2007). The Impact of Postal Voting on Participation: Evidence From Switzerland. Swiss Political Science Review, 13 (2), 167-202. Disponible en: http://dx.doi.org/10.1002/j.1662-6370.2007.tb00075.x.

Lutz, G. (2007). Low Turnout in Direct Democracy. Electoral Studies, 26 (3), 624-632. Disponible en: http://dx.doi.org/10.1016/j.electstud.2006.10.008

Mendelsohn, M. y Parkin, A. (eds.) (2001). Referendum Democracy: Citizens, Elites and Deliberation in Referendum Campaigns. Nueva York: Palgrave.

Morel, L. (1993). Party Attitudes toward Referendums in Western Europe. West European Politics, 16 (3), 225-244. Disponible en: http://dx.doi.org/10.1080/01402389308424972.

Obinger, H. (1998). Federalism, Direct Democracy and Welfare State Development in Switzerland. Journal of Public Policy, 18 (3), 241-263. Disponible en: http://dx.doi. org/10.1017/S0143814X98000129.

Papadopoulos, Y. (2001). How Does Direct Democracy Matter? The Impact of Referendum Votes on Politics and Policy-Making. En J. Lane (ed.). The Swiss Labyrinth: Institutions, Outcomes and Redesign. Londres, Portland: Frank Cass.

Serdült, U. (2010). Referendum Campaign Regulations in Switzerland. En K. Gilland Lutz y S. Hug. Financing referendum campaigns. Nueva York: Palgrave Macmillan. 
- (2014). Referendums in Switzerland. En M. Qvortrup. Referendums around the world. The continued growth of direct democracy. Nueva York: Palgrave Macmillan.

Serdült, U. y Welp, Y. (2012). Direct Democracy Upside Down. Taiwan Journal of Democracy, 8 (1), 69-92.

Tierney, S. (2012). Constitutional Referendums. The Theory and Practice of Republican Deliberation. Oxford: Oxford Constitutional Theory.

- (2014). The Independence Referendum in Scotland: Constructing a Deliberative Process? Ponencia presentada y publicada en The IXth World Congress of Constitutional Law 2014 sobre «Constitutional Challenges: Global and Local», celebrado en Oslo del 16 al 20 de junio de 2014. Disponible en: https://www.jus.uio.no/english/research/newsand-events/events/conferences/2014/wccl-cmdc/wccl/papers/workshop16.html.

Wvortrup, M. (2002). A Comparative Study of Referendums: Government by the People. Manchester: Manchester University Press.

Zolo, D. (1992). Democracy and Complexity: A Realist Approach. Penn: Penn State Press. 